\title{
The Outbreak of COVID-19: A Narrative Thematic Analysis of the Perceived Psychological and health Outcomes
}

\author{
Gyanesh Kumar Tiwari ${ }^{1}$, Pramod Kumar Rai ${ }^{1}$, Abhigyan Dwivedi², and Bablu Ray ${ }^{2}$ \\ ${ }^{1}$ Department of Psychology, School of Humanities \& Social Sciences, Doctor Harisingh \\ Gour Vishwavidyalaya, Sagar, 470003, Madhya Pradesh, India \\ ${ }^{2}$ Department of Linguistics, School of Languages, Doctor Harisingh Gour Vishwavidyalaya, \\ Sagar, 470003, Madhya Pradesh, India
}

May 15, 2020

\begin{abstract}
Objectives: The recent outbreak of COVID-19 has culminated in the unbearable negative life outcomes for all. The study explored the perceived psychological distress and consequent health outcomes caused by COVID-19.

Design: The Narrative Thematic Analysis design was used.

Methods: A heterogeneous sample of 18 participants (12 males and 6 females) responded about their experiences of the recent outbreak of COVID-19. The data were collected through a telephonic semi-structured interview that was analyzed through the Thematic Analysis Method.

Results: Four themes were generated: perceived psychological distress, lower social support, enhanced religious practices and enhanced negative health outcomes. Extreme anxiety, panic experiences, insecurity, helplessness, hyper-vigilance and negative attributions represented the psychological distress while decreased social interactions and imposed social distancing characterized the perceived social support. Increased reliance on myths, divine interpretations and faith in God showed religious practices. Decreased hunger, insomnia, headache, breathing problems and palpitation were ill-health outcomes.

Conclusions: The epidemic was sudden, unknown and fatal that shaped the nature and extent of perceived psychological distress, social support and religious practices. The first two may have caused negative health outcomes while the religious practices maintained equilibrium among the rest three. Immediate trans-disciplinary efforts for the effective prevention, treatment and promotion of the affected people are recommended.
\end{abstract}

\section{Keywords}

COVID-19; pandemic; psychological distress; health consequences; social support; religious practices; narrative thematic analysis.

\section{Introduction}

The recent outbreak of COVID-19 has shaken the whole world. Coronavirus disease (COVID-19) is a respiratory infection caused by the coronavirus that can be transmitted through respiratory droplets and contact routes by droplets particles $(>5-10 \mu \mathrm{m})$ or droplet nuclei $(<5 \mu \mathrm{m})$ (Li et al., 2020; Liu et al., 2020). This disease causes persons to experience mild to moderate respiratory illness that gets recovered without any special treatment. Older people or those suffering from cardiovascular disease, diabetes, chronic respiratory disease and cancer are more prone to develop this disease (World Health Organization, 2020a). According to the World Health Organization (2020b), the confirmed and death cases caused by COVID-19 on April 23, 2020, are 2, 544, 792 and 175, 694, respectively. 
The pandemic of COVID-19 has resulted in many negative consequences on a mass scale involving physical and mental health, social behaviours and relationships, psychological and emotional functioning. A recent review indicated that many negative psychological consequences are associated with the spread of COVID-19 (Brooks et al., 2020). For instance, the study observed that a pandemic like COVID-19 culminates in acute stress, confusion, anger, restrictions, fear of infection, frustration, boredom, poor supplies of goods and services, insufficient information, loss and stigma (Brooks et al., 2020). It has been argued that the vulnerability of COVID-19 may be dissimilar for different persons depending on their social groups, gender, age and socioeconomic status, occupation, health, education, ethnicity, history of physical and psychological illness (disabilities, heart problem, diabetes etc.), economic and social conditions, domicile and working conditions (Pan American Health Organization, 2019).

The consequences of an epidemic involve a set of complex social and psychological processes and these may be very serious if the disease is new, unexpected or very harmful (Strong, 1990). Strong (1990) has argued that the resultant psychological processes are epidemics in themselves that may spread at a fast pace in a variety of forms to individuals and collectives. Epidemic psychology may comprise three types of psychosocial epidemics: fear, explanation and moralization, and the epidemic of action. These may be even more severe when the disease is less well-known (Strong, 1990). These facts may further carry suspicion, insecurity of infection by any method, irrationality, misinformation, panic, stigmatization, avoidance, segregation, abuse and theories of the origin of disease and its effects and metaphysical explanations among educated as well as illiterate people (Weber \& Goldmeier, 1983). It has been argued that epidemic psychology originated from the primitive and irrational unconscious emotions that are universal with different forms and consequences (Strong, 1990).

The ultimate impacts of COVID-19 may be very serious as it has stopped all present human activities across the globe and imposed a sanction on all human interactions. In addition to the disease itself, many negative consequences of the psychological impacts of epidemics have been observed. For example, quarantine has been reported to develop symptoms of acute stress, fatigue, feeling of isolation, anxiety, irritability, insomnia and indecisiveness (Lee et al., 2005; Sprang \& Silman, 2013; Wang et al., 2011). Besides, general psychological symptoms (Mihashi et al., 2009), emotional disturbance (Yoon et al., 2016), depression (Hawryluck et al., 2004) and stress (DiGiovanni et al., 2004) are also caused by quarantine and other restraints. Some qualitative studies have also observed confusion (Pan et al., 2005) and anger (Cava et al., 2005) resulting from quarantine.

It is noticeable from the above discussion that epidemic and its socio-psychological aftermaths lead to a variety of challenges which may catalyze many sorts of psychological distress and poor health outcomes for the affected people. Understanding the dynamics of the psychological distress and negative health outcomes of COVID-19 may be significant for many reasons. The worldwide chaos created after the outbreak of COVID-19 is new, unprecedented and serious as it is the first epidemic which has gripped simultaneously the whole human society for the first time. Previously, epidemics have been limited only to some smaller or larger parts of the world. Besides, the current poor knowledge about the nature, sources and methods of infections of COVID-19 and its ill-effects has created furore never before. The COVID-19 has caused lockdowns in the majority of the human societies of the world. This sudden worldwide lockdown has paralyzed the economic, social, educational, cultural and familial activities and led people to think nothing than Corona. These multiple negative impacts of the outbreak of the disease may have serious psychological and health consequences for all people. In the backdrop of these observations, the present study attempted to explore the impacts of the outbreak of COVID-19 on the perceived psychological distress and health outcomes of a heterogeneous adult sample through the Narrative Thematic Analysis. This method was chosen for two reasons. First, qualitative methods have been suggested to be appropriate for studying phenomena that are either less explicit or lack a guiding framework for the study (Creswell, 2004). Second, it was not possible to collect data on the impacts of COVID-19 on a large scale through quantitative methods as direct contact with the participants was not possible due to the nationwide lockdown in India. 


\section{Methods}

The current study employed a Narrative Thematic Analysis research design that involved a semi-structured interview protocol to collect, process and analyze the data. A heterogeneous sample of 18 participants (age range $=25-56$ years, Mean $=36.22, \mathrm{SD}=8.51$ ) was chosen. These belonged to Sagar, Delhi, Varanasi, Prayagraj, Bangalore and Bhopal cities of India. Initially, 45 individuals were contacted through the telephonic calls. Out of these, only 12 males (age range $=25-56$ years, Mean $=37.33, \mathrm{SD}=$ 9.54 ) and 6 females (age range $=28-44$ years, Mean $=34.00, \mathrm{SD}=6.10)$ gave their consent to respond to their experiences and multiple consequences of the outbreak of the COVID-19 for their life. The descriptions of demographic features are presented in Table 1.

\section{Table . Demographic features of the participants}

A telephonic semi-structured interview was used to collect data. The data was recorded through an audio-recording device available in a mobile phone. The data were analyzed by using the Narrative Thematic Analysis Method (Creswell, 2014). The basic questions covered the sources, causes and impacts of Corona disease on human life. The data collection was started after the approval of the proposal by the Ethics committee [BLINDED FOR REVIEW]. No new themes and codes generating from additional interviews consistent with the research questions were indicative of the saturation (Saunders et al., 2018). Some initial discussions and a pilot study on four participants were carried out to come up with a useful preliminary interview protocol.

Each participant was assigned a code to determine the confidentiality and checking/rechecking of the codes ascertained reliability. The analysis started with reading and rereading the transcriptions to develop familiarity and insights from the data (Barbour, 2001). Early coding of three interviews was done by the authors to assess the appropriateness of the coding framework. The coding framework was assessed regularly to add any significant change in the criteria. Finally, the codes were updated and combined to come up with the relevant codes and to finalize the themes (Guest et al., 2012). According to the suggestions of the American Psychological Association Journal Article Reporting Standards (Levitt et al., 2018), details of the qualitative methods used in this study have been presented in Table 2 .

\section{Table 2. Detailed descriptions of the methods ${ }^{+}$}

\section{Results}

The analysis of the data generated four themes regarding the psychological distress and negative health consequences of COVID-19.

\section{Theme 1: A variety of maladaptive psychological outcomes were closely associ- ated with the outbreak of COVID-19.}

Majority of the participants reported experiences of fear:

I am very afraid that many people will get afflicted by this virus... There is no treatment for this disease. (M_9)

If this lockdown continues, how people could remain alive, what they will eat. (M_11)

People may die of hunger and other diseases... We have heard that even use of currency notes are not safe.......then what is safe? (F_6) 
The pandemic also generated severe apprehension, helplessness and hopelessness in the majority of the participants.

I am very worried about the consequences... It will stop all the income... How essential needs of food, education, employment and social interactions will be satisfied if it continues for long. $\left(\mathrm{F} \_4\right)$

If anyone of my family members will get ill how we will seek medical help... What will happen I don't know? (M_2)

I fear that all citizens of my city will get infected... I have read in the newspaper that one infected person can infect 50000 persons. . . then what will happen. (M_5)

My son studies far away... How he will come back. . how marriage of my relative will happen... crops will be finished... how my business will run. (M_12)

More people will die of hunger rather than the disease itself if it continues. . People may involve in loot and hoarding... Prices will go up. (F_2)

The disease created extreme panic experiences. The participants shared the frequent strange physical and psychological experiences after the outbreak of COVID-19:

Lockdown has stopped all the activities even very important for life. . sometimes I feel dizziness and feeling of insertion in my head. (F_4)

I experience my feelings to be out of control and fragmented... I also frequently experience nausea, the feelings of illness, heaviness of body and its parts especially the heart and less selfcontrol. (M_12)

Likewise, insecurity was reported as a regular feature in their experiences after the outbreak:

Most of our essential needs are based on interactions with other people... How it will be fulfilled... I fear that someone from my family may get infected by this disease. (M_6)

How one will buy food items and vegetables in this restriction... How one can remain safe for long? (F_5)

Loneliness was also a commonly reported feature of their experiences of the disease and restrictions.

The disease has resulted in lockdown... how we will interact with one another? If the problem persists for long (one or two months) it will be very boring and monotonous for everyone. (F_1)

The society will become a zoo with no freedom. (M_10)

Continuous rumination and helplessness experiences were also commonly reported:

I think some untoward to happen... The restrictions are very painful... I frequently think of severe ill-consequences... The prices will go up. (M_7)

How essential needs will be satisfied if the lockdown is again imposed after Mid April? (F_3)

The epidemic made participants hyper-vigilant, feel uncertain and attribute negatively.

Now, I observe precautions... I wash my hands even if I touch anything at home and also ask my family members to do so. (M_3)

I fear of infection... I even do not want to go for a walk just very near to my house. (F_2)

The participants also experienced a feeling of uncertainty in a very serious manner:

I don't understand how far this problem will persist... How long it will take to discover effective medicine or vaccine? (M_9) 
How life will come in order as before. How much time it will take to become everything normal and working? (F_3)

Some participants expressed their negative attributions:

There are some countries which have created this virus for their benefits... The disease is not affecting adults... Only older adults and children will get affected. (M_1)

Villagers too are safe... Many deaths may have occurred even in India than reported... The Government has banned actual reporting of the causalities (M_4).

People say that there is a complete cure in Homeopathy and Ayurveda ... The villagers are safer... It will not affect people from small towns... The disease is a biological weapon (F_5).

Anger, nightmares and nervousness were also frequently experienced by the participants:

When my father asked me about when my son will come back, it gets me angry... It teases me... Staying at one place for a long time has made me irritable. (M_8)

I see many people getting infected and dying of this disease in dreams... once I saw that I got infected... There is no food or water in my house... It makes me nervous... I cannot think what to do and what not to do... Sometimes, I don't feel good... When I think of consequences, I feel down. (F_1)

I am not able to understand what will happen... How my children will come back as lockdown has been imposed for about a month? (M_8)

Theme 2: The outbreak of COVID-19 lowered social interactions and perceived social support.

Most of the participants reported poor interactions, lowered social support, forced social distancing and over-reliance on media caused by the disease. Poor interactions were reported by many:

After the lockdown was announced, I could not understand what to do... I hardly find the opportunity of face-to-face talk to my friends... even unfamiliar due to lockdown. (M_6)

I cannot talk even to my immediate neighbours...... When I look outside from the window of my house I don't see anyone walking over the road. (F_4)

The lowered social support was also reported in good numbers:

I don't believe that a person who has been well-known to me will not come when I will be in need... (F-5)

There is no one to whom I can say to bring my child back to home who has been staying outside for his studies (M_8)

I hesitate to say someone going market for carrying chocolates to my children. (F_2)

My neighbours are not talking to me... They used to visit my home every evening and sit here for hours... We used to walk together every evening... Now, I cannot call anyone even in an emergency. F_6)

Mostly also reported uncomfortable in practising social distancing:

I have to learn how to make a distance from others. (F_1)

Even two persons of the same family are not allowed to ride on a two-wheeler... I have to buy anything from the distance of one meter... It is very irritating. (M_10)

Over-reliance on media was reported to be increased: 
I read everything about this disease from media...... more than ninety per cent messages on WhatsApp and other social media are related to coronavirus. (F_1)

Sometimes I see some contradictory information regarding the disease. (M_5)

\section{Theme 3: Increased religious practices were reported to be associated with the outbreak of COVID-19.}

The participants reported enhanced faith in God and divine interpretations, religious practices and myths.

Enhanced religious practices and faith in God were reported by the majority:

After the outbreak of disease and restrictions on movement, I am regularly praying God to save humanity from this disease. (M_5)

It may be the reflection of the anger of God. I also started observing fast. (F_3)

Only God will save us.... We have started regular Hawan and puja (a kind of sacrifice and worship). (M_7)

I usually don't believe in God... The outbreak of this disease has compelled me to develop a strong faith in God. (M_3)

Worshipping Lord Shiva may help one to be safe from any disease. (F_6)

Observing fast of God Sun may be very helpful in relieving from the pains of this disease. (F_1)

Many myths and divine interpretations were also seen in their reporting:

Someone was telling me that this disease was predicted in a religious book. (M_12)

This disease is the symbol of the anger of God... People have become sinful. (F_1)

Now people do not believe in Pap and Punya (good and bad destiny). (F_4)

Human beings have become opportunists... They deserve it. (M_8)

\section{Theme 4: A variety of physical symptoms were caused by psychological distress and traumatic experiences.}

A multitude of physical ill-health symptoms was reported by the participants.

The uncertainty of lockdown has caused me a regular headache and stomach disturbance. (F_5)

After I have heard about this disease, my hunger has gone down... Usually, I take four to five loaves of bread; now I take only two ... I don't find enough taste in food. (M_7)

Even a small intake of food takes long to get digested... I have developed acidity... My throat burns. (M_11)

The lockdown has lowered my movement... I find my body stiffed. (M_2)

Usually, I used to sleep seven to eight hours... but fear of the unknown has dropped my duration and quality of sleep. (F_2)

Majority of them reported chest pain, tremors, nausea, headache, dizziness, breathing problems, dryness of mouth, stomach disturbance and palpitations.

When I think about the future, I start getting nervous and afraid... Sometimes I feel a slow pain in my chest. (M_3) 
I felt tremors when my father was in the market and the Police were trying to lockdown. (M_6)

My daughter is outside for her studies... When I think about her loneliness and problems, my body gets shivering and mouth gets dry. (F_1)

When I heard people dying of this disease and facing a shortage of food and shelter... It makes me disturbed and my heartbeat frequently becomes abnormal. (F_6)

(Note: Codes from M_1 to M_12 and F_1 to F_6 were assigned to the males and females, respectively.)

\section{Discussion}

The findings proved the contention that the pandemic of COVID-19 catalyzed a variety of perceived psychological distress, poor social support and indulgence in religious practices which may be argued to cumulatively cause many ill-physical symptoms. Extreme fear, anxiety, panic experiences, insecurity, apprehension and helplessness were the chief perceived psychological distress (Theme 1) which may have caused ill-health symptoms (Theme 4). The unexpected, uncertain and threatening nature of COVID-19 makes it a crisis (Seeger et al., 1998). It has been argued that a crisis, if not checked timely, may eventually lead one to face the increasing tension, depression and finally breakdown (Yeager \& Roberts, 2015). The threats to life posed by the pandemic may have led to a set of physiological and psychological responses according to Fight or Flight theory of Cannon which may be appearing in various psychological distress and health symptoms in the participants of the present study (Sellnow \& Seeger, 2013).

The findings may also be explained in terms of the Illness Perceptions Theory which suggests that coping outcomes of stressful situations involve representations, coping responses and appraisal of coping outcomes (Leventhal et al., 1998). As suggested by Leventhal et al. (1998), the basic features of the illness representations (identity, cause, timeline, consequences and curability) acting with the current normative guidelines of the epidemic known to the participants in the present study may be argued to have caused them to perceive psychological distress, decreased social support and to face negative health outcomes. The findings may be further interpreted in terms of Self-Efficacy Theory (Bandura, 1977). Self-efficacy refers to a person's beliefs in his/her abilities to accomplish a task in a given situation according to some accepted criteria (Bandura, 1977). It denotes a sense of control to fulfil environmental demands and to shape positive life outcomes (Bandura, 1997). The current pandemic may have lowered the response efficacy and selfefficacy (de Zwart et al., 2009) which may be the reasons behind the perceived psychological distress and consequent ill-health symptoms of the participants.

The outbreak of the pandemic forced the government to impose mass lockdown and social distancing to check its spreading and to reduce causalities lowered the social interactions and social support (Theme 2). It has been suggested that social support satisfies instrumental, emotional, belongingness, recreational, spiritual, informational and self-esteem needs (Barrera \& Ainlay, 1983). Thus, the lowered social support reported by the participants may have deprived them of these benefits which, in turn, may have aggravated their perceived psychological distress and poor physical health symptoms. As social beings, all humans have a strong need for interactions and for making sense of their world to experience satisfaction, well-being and to live well (Sun et al., 2019). This loss of social connection is significant psychologically for people during the pandemic, but their inability to make sense of this, due to the lack of similar past experiences, challenged their ways of being. The distress caused by poor social interactions may find some comfort by the world-wide shared nature of this experience and collective-consciousness, a need which could be satisfied by religion. Besides, poor social support may have increased apprehension of the unavailability of medical and other facilities leading to perceived distress and increased physical health complaints as reported in previous studies (Reblin \& Uchino, 2008; Zhang et al., 2020).

The pandemic of COVID-19 also increased religious practices and faith in supernatural powers (Theme 3). Religious practices have been suggested to have prophylactic impacts on health and other 
positive life outcomes. For example, religious practices have been observed to cultivate and catalyze meaning, connectedness, wisdom, awareness, adaptive attribution styles, moral judgment, positive relationships and positive self-construal for their adherents irrespective of life and health conditions (Cohen, 2015; Paloutzian, 2013; Sharma et al., 2020). To some extent, these benefits of religious practices may have buffered the effects of perceived psychological distress and poor social support caused by COVID-19 and may have provided some relief from the pains of physical problems. Thus, the pandemic of COVID-19 has caused unwarranted perceived psychological distress and lowered social support which, in turn, may have negatively impacted the physical health. It necessitates that new assumptions and methods should be discovered on a priority basis with their ground in realities which should be able to call individual as well as collective actions to deal with the menace of the epidemic. Besides, positive health practices embedded in different socio-cultural systems may also be explored to help people to face the negative consequences of an epidemic in future. Concerted efforts from researchers, policymakers, health professionals and the public are recommended to face the present and future threats.

\section{References}

Bandura, A. (1977). Self-efficacy: Toward a unifying theory of behavioral change. Psychological Review, 84 (2), 191-215. https://doi.org/10.1037/0033-295X.84.2.191

Bandura, A. (1997). Self-efficacy: The exercise of control. W.H. Freeman.

Barbour, R. S. (2001). Checklists for improving rigour in qualitative research: A case of the tail wagging the dog? BMJ, 322(7294), 1115-1117. https://doi.org/10.1136/bmj.322.7294.1115

Barrera, M., \& Ainlay, S. L. (1983). The structure of social support: A conceptual and empirical analysis. Journal of Community Psychology, 11(2), 133-143. https://doi.org/10.1002/15206629(198304)11:2<133::aid-jcop2290110207>3.0.co;2-1

Brooks, S. K., Webster, R. K., Smith, L. E., Woodland, L., Wessely, S., Greenberg, N., \& Rubin, G. J. (2020). The psychological impact of quarantine and how to reduce it: Rapid review of the evidence. The Lancet, 395(10227), 912-920. https://doi.org/10.1016/S0140-6736(20)30460-8

Cava, M. A., Fay, K. E., Beanlands, H. J., McCay, E. A., \& Wignall, R. (2005). The Experience of Quarantine for Individuals Affected by SARS in Toronto. Public Health Nursing, 22(5), 398-406. https://doi.org/10.1111/j.0737-1209.2005.220504.x

Cohen, A. B. (2015). Religion's Profound Influences on Psychology: Morality, Intergroup Relations, Self-Construal, and Enculturation. Current Directions in Psychological Science, 24(1), 77-82. https://doi.org/10.1177/0963721414553265

Creswell, J. W. (2004). Designing A Mixed Methods Study In Primary Care. The Annals of Family Medicine, 2(1), 7-12. https://doi.org/10.1370/afm.104

Creswell, J. W. (2014). Research design: Qualitative, quantitative, and mixed methods approaches (4th ed). SAGE Publications.

de Zwart, O., Veldhuijzen, I. K., Elam, G., Aro, A. R., Abraham, T., Bishop, G. D., Voeten, H. A. C. M., Richardus, J. H., \& Brug, J. (2009). Perceived Threat, Risk Perception, and Efficacy Beliefs Related to SARS and Other (Emerging) Infectious Diseases: Results of an International Survey. International Journal of Behavioral Medicine, 16(1), 30-40. https://doi.org/10.1007/s12529-008-9008-2

DiGiovanni, C., Conley, J., Chiu, D., \& Zaborski, J. (2004). Factors Influencing Compliance with Quarantine in Toronto During the 2003 SARS Outbreak. Biosecurity and Bioterrorism: Biodefense Strategy, Practice, and Science, 2(4), 265-272. https://doi.org/10.1089/bsp.2004.2.265

Guest, G., MacQueen, K. M., \& Namey, E. E. (2012). Applied thematic analysis. Sage Publications. 
Hawryluck, L., Gold, W. L., Robinson, S., Pogorski, S., Galea, S., \& Styra, R. (2004). SARS Control and Psychological Effects of Quarantine, Toronto, Canada. Emerging Infectious Diseases, 10(7), 1206-1212. https://doi.org/10.3201/eid1007.030703

Lee, S., Chan, L. Y. Y., Chau, A. M. Y., Kwok, K. P. S., \& Kleinman, A. (2005). The experience of SARS-related stigma at Amoy Gardens. Social Science \& Medicine, 61(9), 2038-2046. https://doi.org/10.1016/j.socscimed.2005.04.010

Leventhal, H., Leventhal, E. A., \& Contrada, R. J. (1998). Self-regulation, health, and behavior: A perceptual-cognitive approach. Psychology $\&$ Health, 13(4), 717-733. https://doi.org/10.1080/08870449808407425

Levitt, H. M., Bamberg, M., Creswell, J. W., Frost, D. M., Josselson, R., \& Suárez-Orozco, C. (2018). Journal article reporting standards for qualitative primary, qualitative meta-analytic, and mixed methods research in psychology: The APA Publications and Communications Board task force report. American Psychologist, 73(1), 26-46. https://doi.org/10.1037/amp0000151

Li, Q., Guan, X., Wu, P., Wang, X., Zhou, L., Tong, Y., Ren, R., Leung, K. S. M., Lau, E. H. Y., Wong, J. Y., Xing, X., Xiang, N., Wu, Y., Li, C., Chen, Q., Li, D., Liu, T., Zhao, J., Liu, M., .. Feng, Z. (2020). Early Transmission Dynamics in Wuhan, China, of Novel Coronavirus-Infected Pneumonia. New England Journal of Medicine, 382(13), 1199-1207. https://doi.org/10.1056/NEJMoa2001316

Liu, J., Liao, X., Qian, S., Yuan, J., Wang, F., Liu, Y., Wang, Z., Wang, F.-S., Liu, L., \& Zhang, Z. (2020). Community Transmission of Severe Acute Respiratory Syndrome Coronavirus 2, Shenzhen, China, 2020. Emerging Infectious Diseases, 26(6). https://doi.org/10.3201/eid2606.200239

Mihashi, M., Otsubo, Y., Yinjuan, X., Nagatomi, K., Hoshiko, M., \& Ishitake, T. (2009). Predictive factors of psychological disorder development during recovery following SARS outbreak. Health Psychology, 28(1), 91-100. https://doi.org/10.1037/a0013674

Paloutzian, R. F. (2013). Psychology of Religion. In A. L. C. Runehov \& L. Oviedo (Eds.), Encyclopedia of Sciences and Religions (pp. 1904-1910). Springer Netherlands. https://doi.org/10.1007/978-1-4020-8265-8_939

Pan American Health Organization. (2019). Public Policies and Health System and Services. Pan American Health Organization Editors: Pan American Health Organization. https://iris.paho.org/handle/10665.2/51542

Pan, P. J. D., Chang, S.-H., \& Yu, Y.-Y. (2005). A Support Group for Home-Quarantined College Students Exposed to SARS: Learning from Practice. The Journal for Specialists in Group Work, 30(4), 363-374. https://doi.org/10.1080/01933920500186951

Reblin, M., \& Uchino, B. N. (2008). Social and emotional support and its implication for health: Current Opinion in Psychiatry, 21(2), 201-205. https://doi.org/10.1097/YCO.0b013e3282f3ad89

Saunders, B., Sim, J., Kingstone, T., Baker, S., Waterfield, J., Bartlam, B., Burroughs, H., \& Jinks, C. (2018). Saturation in qualitative research: Exploring its conceptualization and operationalization. Quality $\mathcal{E}$ Quantity, 52(4), 1893-1907. https://doi.org/10.1007/s11135-017-0574-8

Seeger, M. W., Sellnow, T. L., \& Ulmer, R. R. (1998). Communication, Organization, and Crisis. Annals of the International Communication Association, 21 (1), 231-276. https://doi.org/10.1080/23808985.1998.11678952

Sellnow, T. L., \& Seeger, M. W. (2013). Theorizing crisis communication. Wiley-Blackwell.

Sharma, D. N., Tiwari, G. K., \& Rai, P. K. (2020). The spiritual beliefs of cancer survivors: A thematic analysis. Psychology, Community $\&$ Health, 8(1), 139-157. https://doi.org/10.5964/pch.v8i1.290

Sprang, G., \& Silman, M. (2013). Posttraumatic Stress Disorder in Parents and Youth After 
Health-Related Disasters. Disaster Medicine and Public Health Preparedness, 7(1), 105-110. https://doi.org/10.1017/dmp.2013.22

Strong, P. (1990). Epidemic psychology: A model. Sociology of Health and Illness, 12(3), 249-259. https://doi.org/10.1111/1467-9566.ep11347150

Sun, J., Harris, K., \& Vazire, S. (2019). Is well-being associated with the quantity and quality of social interactions? Journal of Personality and Social Psychology. https://doi.org/10.1037/pspp0000272

Wang, Y., Xu, B., Zhao, G., Cao, R., He, X., \& Fu, S. (2011). Is quarantine related to immediate negative psychological consequences during the 2009 H1N1 epidemic? General Hospital Psychiatry, 33(1), 75-77. https://doi.org/10.1016/j.genhosppsych.2010.11.001

Weber, J., \& Goldmeier, D. (1983). Medicine and the Media. British Medical Journal, 287(6389), 420-420. https://doi.org/10.1136/bmj.287.6389.420

World Health Organization. (2020a). Coronavirus. https://www.who.int/westernpacific/healthtopics/coronavirus

World Health Organization. (2020b). Coronavirus disease 2019 (COVID-19) Situation Report-94. https://www.who.int/docs/default-source/coronaviruse/situation-reports/20200423-sitrep-94-covid-

19.pdf?sfvrsn=b8304bf0_4

Yeager, K. R., \& Roberts, A. R. (2015). Bridging the Past and Present to the Future of Crisis Intervention and Crisis Management. In K. R. Yeager \& A. R. Roberts, Crisis Intervention Handbook: Assessment, Treatment, and Research (Fourth, pp. 3-35). Oxford University Press.

Yoon, M.-K., Kim, S.-Y., Ko, H.-S., \& Lee, M.-S. (2016). System effectiveness of detection, brief intervention and refer to treatment for the people with post-traumatic emotional distress by MERS: A case report of community-based proactive intervention in South Korea. International Journal of Mental Health Systems, 10(1), 51. https://doi.org/10.1186/s13033-016-0083-5

Zhang, J., Wu, W., Zhao, X., \& Zhang, W. (2020). Recommended psychological crisis intervention response to the 2019 novel coronavirus pneumonia outbreak in China: A model of West China Hospital. Precision Clinical Medicine, 3(1), 3-8. https://doi.org/10.1093/pcmedi/pbaa006 